\title{
An atomic force microscopy study of coal nanopore structure
}

\author{
YAO SuPing ${ }^{*}$, JIAO Kun, ZHANG Ke, HU WenXuan, DING Hai, LI MiaoChun \& \\ PEI WenMing
}

State Key Laboratory for Mineral Deposits Research, School of Earth Sciences and Engineering, Nanjing University, Nanjing 210093, China

Received January 27, 2011; accepted May 31, 2011

\begin{abstract}
Coal nanopore structure is an important factor in understanding the storage and migration of absorbed gas in coal. A new method for studying coal nanopore structures is proposed. This idea is based on the nano-level resolution of atomic force microscopy, which can be employed to observe the structural features of coal nanopores clearly, conduct quantitative three-dimensional measurements and obtain structural parameters. Analysis results show that coal nanopores are mainly metamorphic pores and intermolecular pores. The metamorphic pores are commonly rounded and elliptical, increasing quantitatively with the coalification degree. The forms of intermolecular pores change markedly. The average pore size of low-rank coal is bigger than high-rank coal, and the number of intermolecular pores decreases as the coal rank increases. Section analysis effectively characterizes the coal pore microstructure, bearing analysis is a vital approach to measure microporosity, and grain analysis can be employed to study the pore size distribution. Atomic force microscopy is a tool for the in-depth research of coal pore microstructure and the coal-bed methane adsorption mechanism.
\end{abstract}

coal nanopore, atomic force microscopy, coal-bed methane, pore size distribution, porosity

Citation: $\quad$ Yao S P, Jiao K, Zhang K, et al. An atomic force microscopy study of coal nanopore structure. Chinese Sci Bull, 2011, 56: 2706-2712, doi: 10.1007/ s11434-011-4623-8

The characteristics of coal pores have attracted wide attention from scholars around the world because of the multiple needs of coal-bed methane exploration and development, and $\mathrm{CO}_{2}$ injection and underground storage. The pore structure and porosity of coal, which is a complicated and porous solid, affect not only the migration behavior of coalbed gas but also its storage and adsorption mechanisms [1-7]. There are several categories of coal pore systems. Xodot used the diameter to classify pores as micropores $(<0.01 \mu \mathrm{m})$, small pores $(0.01-0.1 \mu \mathrm{m})$, mesopores $(0.1-1$ $\mu \mathrm{m})$ and macropores $(>1 \mu \mathrm{m})$ [8]. Gan et al. [9] classified coal pores as micropores $(0.4-1.2 \mathrm{~nm})$, transitional pores $(1.2-30 \mathrm{~nm})$ and macropores $(>30 \mathrm{~nm})$. Zhang [10] divided coal pores into primary pores, metamorphic pores, epigenetic pores and mineral pores according to scanning electron microscopy (SEM) and found that pore diameters were generally larger than $1000 \mathrm{~nm}$. The features of these

*Corresponding author (email: spyao@nju.edu.cn) macropores are of great importance to free gas storage and migration; however, small pores and micropores, which are difficult to observe under normal microscopes and through SEM because their diameters are smaller than $100 \mathrm{~nm}$, have an important role in adsorbed-gas storage and migration.

Nowadays, methods of characterizing coal nanopore structure, pore size distribution, porosity and other fractal properties mainly comprise mercury porosimetry, use of the nitrogen adsorption isotherm, SEM, transmission electron microscopy, small-angle X-ray scattering and neutron scattering analysis. Because of the compressibility of coal and the average pore sizes being of nanoscale, it is difficult to characterize pore size distribution and pore structure in depth with common methods such as quantitative measurements of the nitrogen adsorption isotherm and mercury porosimetry. Limited by resolution and other disadvantages, SEM can barely observe coal nanopores. Therefore, there is largely no existing measurement to directly observe the coal nanopore structure and quantitatively measure porosity. 
Atomic force microscopy (AFM) is a tool for studying the microscopic world. Capable of using and measuring van der Waals forces, AFM is a new super-resolution near-field probe microscopic technique that can be applied to both conductors and insulators. Most existing indirect or calculation procedures estimate the internal surface structure of coal samples, and the images obtained by such methods are limited to two dimensions; moreover, little information is available for a polished surface. AFM can provide in situ, real-time, real-space and high-resolution images of the sample surface. AFM can also provide dynamic threedimensional images of the sample surface and quantitative information $[11,12]$ and thus transcends the planar imaging of other instruments. Compared with other current surface analysis techniques, AFM has the advantage of low requirements for sampling procedures and working environment. As a tool for measuring the surface physical properties of various samples, AFM has been widely applied in materials science and life science [12-17].

Even though AFM is widely used in other fields, it has been employed in few studies on coal. Yumura et al. [18] observed the surface topography and characteristics of the coal pore structure employing AFM. Lawrie et al. [19] examined and analyzed the pore structure of coal macerals and were the first to use the section analysis technique of AFM to measure coal porosity. Cohen et al. [20] and Bruening et al. [21] observed the surface topography of vitrinite and inertinite in coal and analyzed the roughness and hardness of the maceral surface using the quantitative function of AFM. Golubev et al. [22] observed the supermolecular structure of natural bitumen and put forward the metamorphic evolution model. Additionally, Chinese scholars have tentatively used AFM to observe the coal surface structure. Yang et al. [23] observed anthracite by AFM and preliminarily obtained high-quality images of the coal surface. Chang et al. [24] conducted a preliminary AFM observation of the pore structure of the coal surface. Liu et al. [25] quantitatively measured the surface characteristics and roughness of superfine pulverized coal particles of different diameters. Even though the observing range of AFM is limited, primitive observations of the coal pore structure show the great potential of AFM applications [13-15]. This paper describes the employment of AFM technology in research on coal nanopores. Possessing the unique advantage of highresolution imaging and various quantitative analyses, AFM is used to observe the coal pore structure of different coal ranks and analyze the pore size distribution and porosity quantitatively to provide scientific evidence for the adsorption mechanism of coal-bed methane and prediction of coalmine gas outbursts.

\section{Samples and methods}

A NanoScope III atomic force microscope manufactured by
Digital Company (Santa barbara, California, USA) was used in the experiment. The maximum scanning range was $90 \mu \mathrm{m} \times 90 \mu \mathrm{m} \times 5 \mu \mathrm{m}$ and the maximum resolution was $0.2 \mathrm{~nm}$ horizontally and $0.03 \mathrm{~nm}$ vertically (mica calibration). A microcantilever tip was used. As the force sensor contacts and undulates with the sample surface when detecting, the distance between the tip and the sample surface is of nanometer scale. If the undulation of the measured sample surface goes beyond that of the force sensor, the system cannot scan normally and there is even the possibility that the tip will be damaged [26]. Therefore, the AFM requires the sample surface to be as smooth as possible. A natural surface with possibly greater smoothness or a milled surface should be prepared for AFM scanning. In this paper, the samples were cut or ground into slices with an approximate area of $1 \mathrm{~cm}^{2}$, and then both the observation plane and backside were milled finely to ensure smoothness. Before observation, anhydrous ethanol was used to remove any impurities adsorbed on the sample surface. The contact mode, which provides stable and high-resolution imaging, was employed in our experiment. The scanning data were processed and analyzed with NanoScope III Version $5.12 \mathrm{~b} 48$ software [11].

The experimental samples were mainly bituminous coal and anthracite taken from the Pingle Depression in Jiangxi Province, China. More information on the samples is presented in Table 1.

\section{Results and discussion}

\subsection{Features and structure of pores}

Figure 1 shows AFM images of coal surfaces of different coal ranks. Figure 1(a) is the three-dimensional image of a wide scanning range $(5 \mu \mathrm{m} \times 5 \mu \mathrm{m})$ of the low-rank gas coal surface. In Figure 1(b), the range is $2 \mu \mathrm{m} \times 2 \mu \mathrm{m}$, and the features of the nanopores are clear. The most common pore shape is rounded followed by elliptical, with all pores having smooth walls and clear outlines. Pores are mainly mesopores $(>100 \mathrm{~nm})$, which are isolated or linked with cracks. Nevertheless, there are only a small number of scattered mesopores on the coal surface, while small pores and micropores are not well developed either. Figure 1(c) is the AFM image of the high-rank anthracite surface. The coal surface is mainly covered by small pores and micropores although there are also other differently sized pores present. Comparing with the low-rank gas coals, there are many

Table 1 Characteristics of experiment samples

\begin{tabular}{llccl}
\hline Sample & Sampling sites & $R_{\mathrm{o}}(\%)$ & Geological age & Coal rank \\
\hline Spm & Jiangxi Leping & 0.67 & $\mathrm{P}_{3} \mathrm{l}$ & Gas coal \\
CX & Zhejiang Changxing & 0.72 & $\mathrm{P}_{3} \mathrm{l}$ & Gas coal \\
Qs & Jiangxi Pingxiang & 2.47 & $\mathrm{~T}_{3} \mathrm{a}$ & Anthracite \\
SX & Jiangxi Fengcheng & 4.34 & $\mathrm{~T}_{3} \mathrm{a}$ & Anthracite \\
\hline
\end{tabular}



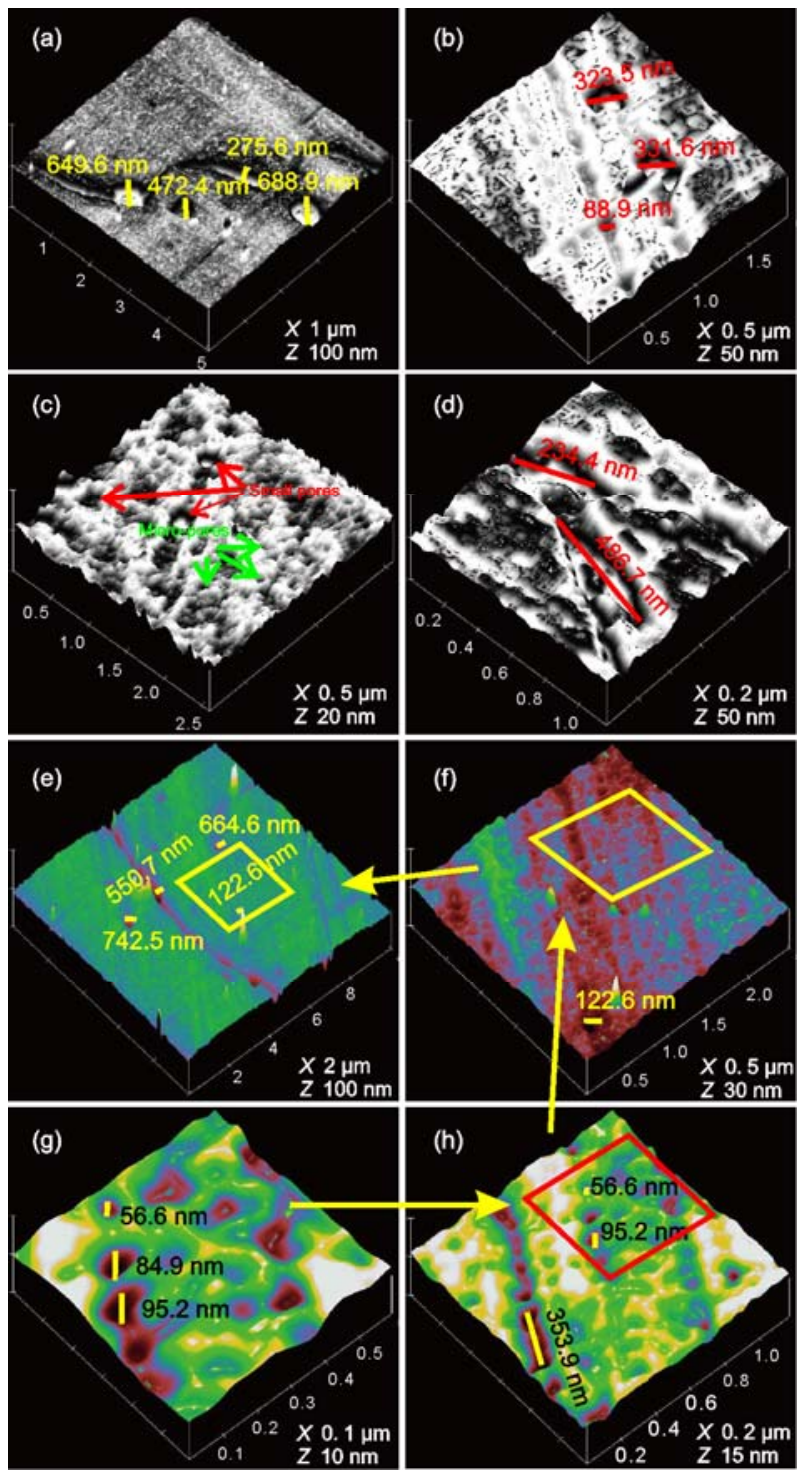

Figure 1 AFM images of nanopores in coal. (a) Microcracks and pores in coal; gas coal, Changxing, Zhejiang Province, $\mathrm{P}_{3}$ l. (b) Same as (a) but for mesopores and small pores in coal. (c) A large number of micropores in coal; anthracite, Pingxiang, Jiangxi Province, $\mathrm{T}_{3} \mathrm{a}$. (d) Irregular-shaped micropores in coal; anthracite, Fengcheng, Jiangxi Province, $T_{3}$ a. Figures (e), (f), (g), and (h) are successively partially enlarged views of sample QS. $X$ stands for the graduation of $x$-axis (level axis), while $Z$ stands for the graduation of $z$-axis (vertical axis). $X$ and $Z$ stand for the same meaning hereafter.

more micropores on the coal surface. Figure 1(e)-(h) is enlarged series of zoomed-in images of an anthracite sample taken by AFM. In the large-scale images, only the features of the cracks and the mesopores can be observed. Zooming in gradually, the complex microtopography of the coal surface is revealed, and many small pores and micropores are clearly exposed. These pores are mainly rounded, while there are also irregular pores such as elliptical, pear-shaped, and lunate-shaped pores (Figure 1(c)-(h)) [13,27]. As shown in Figure 1(d), a pore has a curved edged, with coal microparticles within. Several micropores can connect to form larger irregular-shaped pores or beaded microfissures (Figure 1(c), (f), (g), (h)). The appearance and occurrences of pores indicate that most of these pores are metamorphic [10] or thermogenic [9]. Loucks et al. [28] observed nanopores in the grains of organic matter in Barnett shale employing SEM and found that a single grain of organic matter could contain hundreds of pores with porosity up to $20.2 \%$. The intraparticle organic pores mostly have irregular or elliptical cross sections and ranged between 5 and $750 \mathrm{~nm}$ in width (the median pore size is about $100 \mathrm{~nm}$ ). According to these observations, the intraparticle organic pores, which are equivalent to metamorphic pores or thermogenic pores previously described, are considered to be related to thermal maturation. The figure reveals that pores in low metamorphic bituminous coal are usually isolated without obvious connections (Figure 1(a),(b)). There are more anthracite micropores present in an irregular network than those in low-rank coals (Figures 1(c), (d)). Quantitative analysis shows that the pore density is $5.33 \times 10^{5} / \mathrm{mm}^{2}$ in gas coal (sample Spm) and $2.57 \times 10^{6} / \mathrm{mm}^{2}$ in anthracite (sample QS) (Table 3), indicating that with the increase in coal rank, the metamorphic porosity of coal increases [29-31]. Coal metamorphism is a process in which the polycyclic aromatic system increases the condensation degree under the effect of temperature and pressure, decreasing and shortening the side chains gradually at the same time and resulting in a gradual increase in the aromatization degree. Metamorphic pores form during the hydrocarbon generation and concentration process in coal metamorphism. Moreover, quantitative analysis results indicate that the observed pores are mostly metamorphic pores. Because coal nanopores greatly affect gas adsorption, many scholars have investigated pore characteristics of coal such as pore volume, pore-throat distribution, and pore structure. However, the classification of coal pores is based on a mercury ejection curve or nitrogen adsorption isotherm $[27,32]$, and the coal pore morphology is indirectly inferred. Using AFM, the morphology and distribution of various types of pores that support coal pore classification with vital evidence are revealed directly, providing a crucial reference for the geometric study of the coal pore structure.

Figure 2 presents high-resolution images of gas coal and anthracite; the range is $500 \mathrm{~nm} \times 500 \mathrm{~nm}$ (Figure 2(a), (c)) and $125 \mathrm{~nm} \times 125 \mathrm{~nm}$ (Figure 2(b), (d)). Low-rank coal has a loose grid structure, while anthracite has a tight grid array structure. This grid structure of alternating light and dark surface characteristics might be the result of the close packing of large molecules [23], and the main outline of the grid structure may be constituted by a macromolecule in the form of 'nanowires'. The light spot on the nanowire (the green protrusion of the surface in the two-dimensional image) may be the location of complicated macromolecular compounds containing different kinds of aliphatic and non aliphatic functional groups. These compounds with bridge bonds are mainly derived from the lignin condensed aro- 

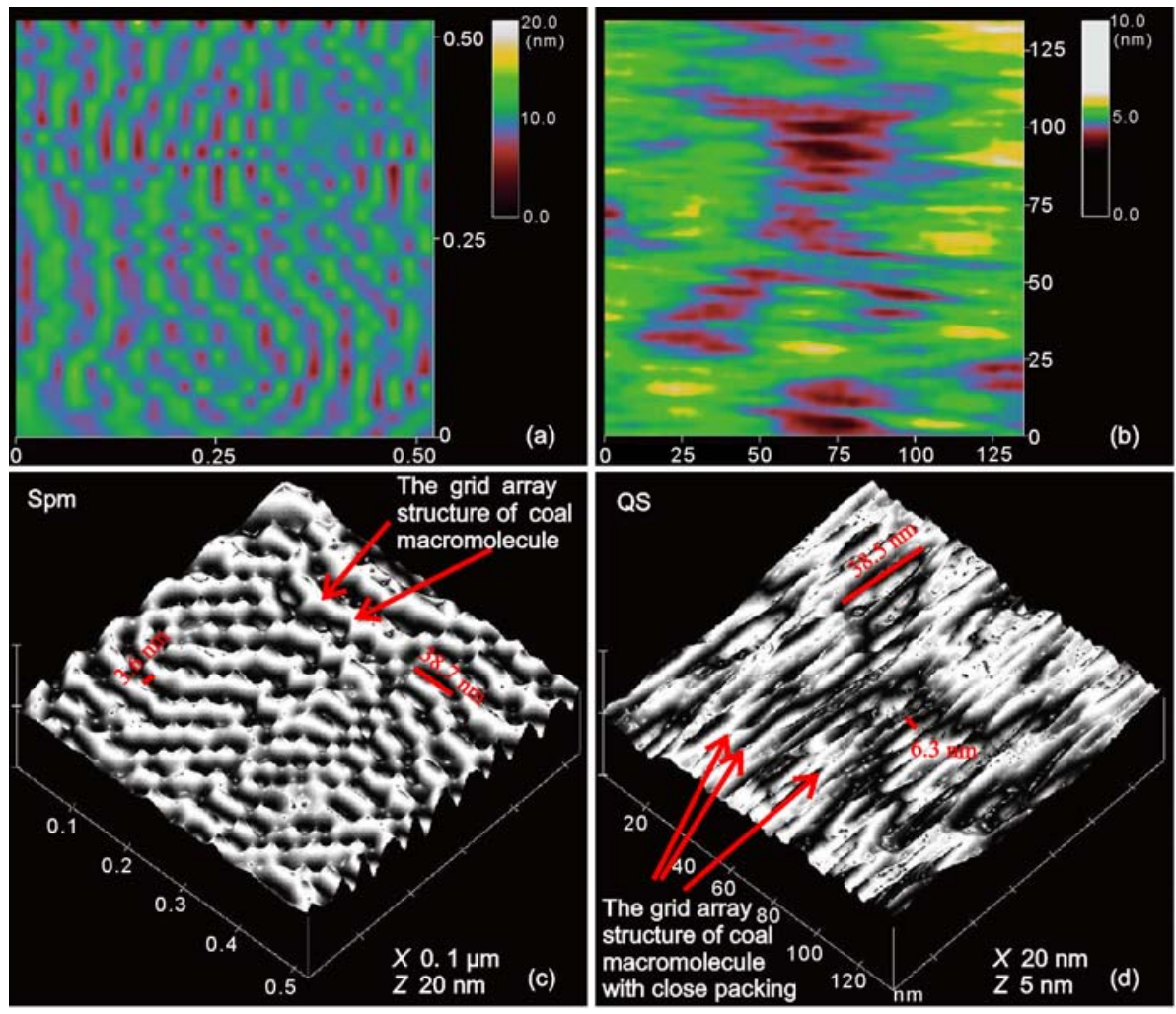

Figure 2 AFM image of molecular pores in coal. (a) Coal macromolecules are arranged as a loose grid structure; the green protrusion of the surface is a 'nanowire' of coal macromolecules; the dark red depression between adjacent nanowires is an intermolecular pore; gas coal, Leping, Jiangxi Province, $\mathrm{P}_{3}$ l. (b) The grid array structural features of the closely packed accumulation of coal macromolecules; anthracite, Pingxiang, Jiangxi Province, $\mathrm{T}_{3} \mathrm{a}$. (c) Same as (a) but a three-dimensional image. (d) Same as in (b) but a three-dimensional image.

matic nucleus. The dark area between the adjacent nanowires (the dark red depression in the two-dimensional image) may be pores between the skeletons in the polymer main chain $[12,15,22,23]$. The intermolecular pores of gas coal are mainly rounded and elliptical, with a short-axis diameter range from 2 to $7 \mathrm{~nm}$ and an average of around 3.5 $\mathrm{nm}$; the long-axis diameter varies greatly, occasionally reaching the size of mesopores. Because of the close packing of macromolecules in the anthracite, the grid spacing reduces greatly, and the pore space between macromolecular chains is severely compressed in anthracite compared with that in gas coal. However, pore structure exists in the skeletons of the polymer main chain (Figure 2(d)), which may result from the rupture of the branched chain and the dropout of functional groups in the main chain during coal metamorphism. The small pores or micropores are mainly elliptical or elongated with short axis diameters less than 10 $\mathrm{nm}$. The properties of the coal macromolecular structure determine the development of micropores in coal. The structural unit of low-rank coal has numerous side chains and functional groups, usually with low aromaticity. Moreover, the radius of the low-rank coal molecules is large with the loose packing of macromolecules, the combination of structural units is not compact, and the pores between the molecules are well developed. The AFM images of gas coals reveal a loose arrangement of macromolecules, which leads to well-developed intermolecular pores between the macromolecular chains [10]. The intermolecular pores between the molecule chains are a result of the polycondensation of the gelling organic matter during coalification. The structure of high-rank coals has a smaller molecular radius, a high degree of aromatization and dense accumulation of macromolecules as a result of a great loss of side chains and functional groups. AFM shows that the intermolecular pores have decreased in number and that some have changed into fairly large micropores and small pores.

The intermolecular pores in the low-rank coal were thought to be larger than those in the high-rank coal by Zhang et al., and as the coal rank increases, the intermolecular pores could slowly evolve into molecular structured pores [10]. The structural units of anthracite macromolecules have been suggested to start to 'crystallize' because of the overlapping actions [33], resulting in a sharp drop in the number of pores in coal. All these considerations suggest that with an increase in coal rank, the arrangement of the macromolecules in coal becomes tighter, the molecular chains are squeezed, and the pores between molecules gradually decrease in size.

\subsection{Pore size distribution and porosity analysis}

AFM can determine the surface nature of samples under 
contact mode employing several methods such as section, grain and bearing analyses [11,21]. Section analysis analyzes a profile of the scanning area of the sample, revealing the undulating vertical distance and surface roughness along the section, and thus measures the diameter and depth of pores. In terms of the accessibility to measure the pore area and grain area of coal, grain analysis is a fast and efficient method for determining pore size distribution. Bearing analysis characterizes the surface nature and pore/grain distribution of different heights of the scanned area (to calculate the grain (non-pore) area and area/pore ratio above or below the selected height) and thus measures areal porosity.

Figure 3 shows a large number of micropores with various shapes in the anthracitic samples; however, we could only observe the qualitative pore morphology and compare relative pore size from the image. Figure 4 is the section analysis of Figure 3(a); the direction and length of the section is marked in Figure 3(a). The diameter and depth of pores in the section can be measured in Figure 4, which shows that the largest pore in the section has a diameter of $354.4 \mathrm{~nm}$ and pore depth of $13.5 \mathrm{~nm}$, while the smallest pore has a diameter of $33.2 \mathrm{~nm}$ and depth of $1.6 \mathrm{~nm}$.
The No. 7 pore is the median pore in the section and has a diameter of $59.7 \mathrm{~nm}$ and depth of $3.3 \mathrm{~nm}$. Among the 10 pores in the section, only one is a mesopore while the others are either micropores or small pores with a diameter less than $100 \mathrm{~nm}$ and depth less than $10 \mathrm{~nm}$. Further statistics on the 6380 pores in the $500 \mu \mathrm{m}$ length section indicate that there are 5227 micropores and small pores, accounting for $83.5 \%$ of all pores, with micropores being the main pore type in anthracite. The image of the pore appearance (Figure 3 ) shows the pore wall is generally smooth and rounded; however, the section analysis shows the structure of micropores is complex, as the pore wall of the pores irregularly undulates.

Figure 5 is a fracture cross-section. The whole figure has an area of $2.994 \mu^{2}$, while the area of the smallest pore is $381.47 \mathrm{~nm}^{2}$ and the average pore area is $54540 \mathrm{~nm}^{2}$. The total pore area and the areal porosity above the datum plane are $6.752 \mu \mathrm{m}^{2}$ and $6.752 \%$, respectively (Table 2). Because the scanning area is limited in the bearing and grain analyses of one AFM image, increasing the analyzed area obviously enhances the representativeness of the sample; much data should be used in AFM grain and bearing analysis to
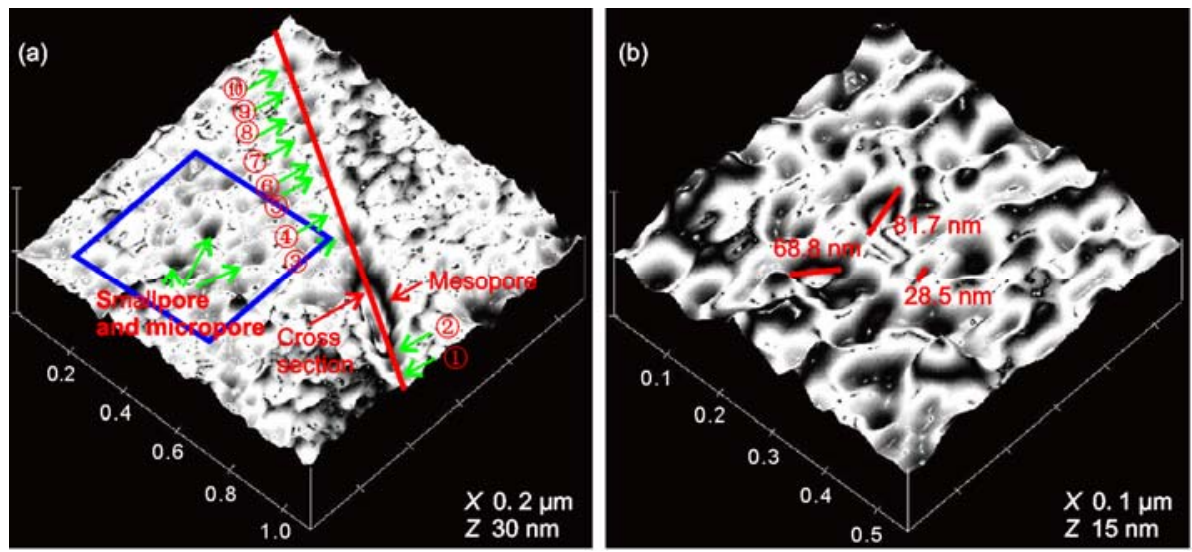

Figure 3 Appearances of differently sized pores in coal. (a) Anthracite, Pingxiang, Jiangxi Province, $\mathrm{T}_{3} a$; (b) magnification of the rectangular area indicated in (a).

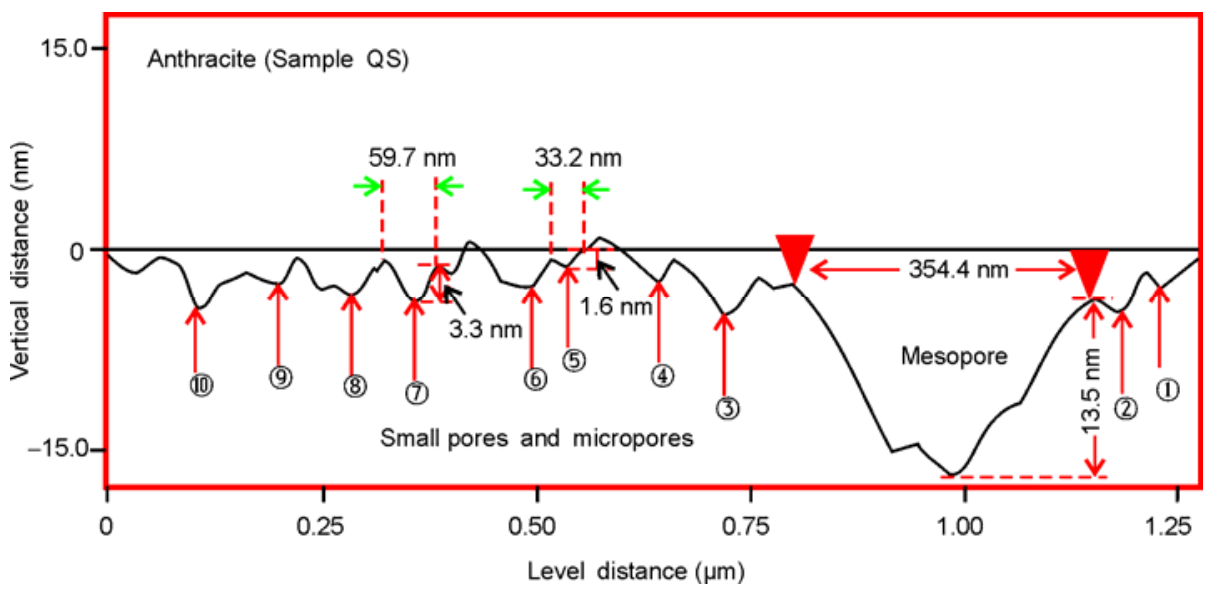

Figure 4 Section analysis of AFM (the section is indicated in red in Figure 3(a)). 

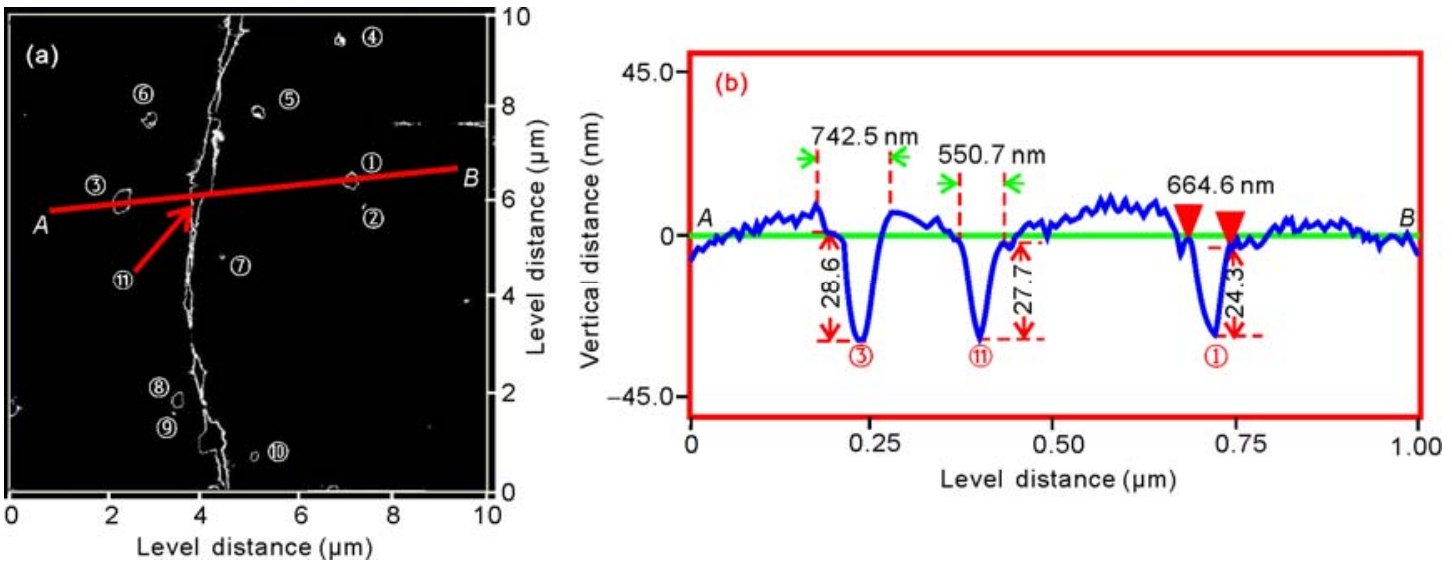

Figure 5 Analysis of pore diameter (anthracite, Jiangxi Pingxiang, $\mathrm{T}_{3} a$ ). (a) Pore distribution; (b) section analysis of line $A B$ in (a).

quantitatively study the pore structure. The quantitative analysis of the pore nature of relatively large areas is presented in Table 3. The statistical data of the scanning area (Table 3) imply that the pore number in anthracite is five times that in gas coal, and the areal porosity of anthracite is also higher; however, the average pore size in anthracite is obviously smaller than that in gas coal, indicating greater numbers of micropores, small pores and mesopores and greater areal porosity in anthracite. The hydrocarbon generation of coal with an increase in coalification degree (maturity) could account for the increase in pore size and has been presented by other scholars [29-31,34,35]. Hover et al. [36] employed transmission electron microscopy to observe organic matter in low metamorphic shale, finding no nanopores. Loucks et al. [28] employed SEM to study Barnett shale, discovering large numbers of nanopores in macerals of the samples with Ro ranging from $1.3 \%$ to $1.6 \%$. Employing AFM to quantitatively analyze pores requires com- plicated statistics; however, direct observation and quantitative analysis gives AFM a unique advantage. Analyzing the pore size and porosity of coal by AFM is a rapid, convenient, and quantitative new method that is also important to theoretical and applied research on the pore structure of unconventional gas reservoirs such as shale and tight sandstone $[37,38]$.

\section{Conclusions}

AFM, which can be employed to visually observe the pore microstructure of coal, obtains three-dimensional images that dynamically show the pore and fracture distribution in coal and quantitatively measures coal nanopores in different planes and various angles. AFM thus promotes research into pore microstructure at a molecular level and provides a new method for research on pore microstructure, the pore size

Table 2 Analysis of pore diameter and bearing analysis of anthracite in Figure 5 (Sample QS)

\begin{tabular}{|c|c|c|c|c|c|}
\hline \multirow{2}{*}{\multicolumn{2}{|c|}{ Analysis of automatic pore identification }} & \multicolumn{4}{|c|}{ Quantitative analysis of selected pore } \\
\hline & & \multirow{2}{*}{$\begin{array}{c}\text { Pore No. } \\
1\end{array}$} & \multirow{2}{*}{$\frac{\text { Area of pore }\left(\mathrm{nm}^{2}\right)}{138092}$} & \multirow{2}{*}{$\frac{\text { Pore No. }}{7}$} & \multirow{2}{*}{$\frac{\text { Area of pore }\left(\mathrm{nm}^{2}\right)}{2629}$} \\
\hline Total pore account & 77 & & & & \\
\hline Area of the smallest pore $\left(\mathrm{nm}^{2}\right)$ & 381.47 & 3 & 188827 & 9 & 2044 \\
\hline Area of the largest pore $\left(\mu \mathrm{m}^{2}\right)$ & 2.994 & 4 & 59890 & 10 & 40054 \\
\hline Total area of pores $\left(\mathrm{nm}^{2}\right)$ & 6752000 & 5 & 75531 & 11 & 2994000 \\
\hline Areal porosity $(\%)$ & 6.752 & 6 & 57056 & & \\
\hline
\end{tabular}

Table 3 Quantitative analysis results of automatic identification of different sample pores (scanning area is $50000 \mu \mathrm{m}^{2}$ )

\begin{tabular}{lccccc}
\hline Sample & $\begin{array}{c}\text { Pores account } \\
\left(\mathrm{mm}^{-2}\right)\end{array}$ & $\begin{array}{c}\text { Average area of pores } \\
\left(\mathrm{nm}^{2}\right)\end{array}$ & $\begin{array}{c}\text { Area of the smallest } \\
\text { pore }\left(\mathrm{nm}^{2}\right)\end{array}$ & $\begin{array}{c}\text { Area of the } \\
\text { largest pore }\left(\mathrm{nm}^{2}\right)\end{array}$ & $\begin{array}{c}\text { Total area of pores } \\
\left(\mu \mathrm{m}^{2}\right)\end{array}$ \\
\hline Spm & $5.33 \times 10^{5}$ & 71816 & 167 & 12260000 & 1915 \\
CX & $5.55 \times 10^{5}$ & 74829 & 132 & 99280000 & 3.83 \\
QS & $2.57 \times 10^{6}$ & 23871 & 56 & 4285000 & 3.18 \\
SX & $3.32 \times 10^{6}$ & 19441 & 48 & 5521000 & 3075 \\
\hline
\end{tabular}


distribution, porosity and other parameters of a coal reservoir. Our research shows that section analysis effectively characterizes the pore microstructure of coal, bearing analysis is important to the characterization of microporosity, and grain analysis could be employed to study the pore size distribution. Nanopore research employing AFM can provide more detailed information for the further study of the coal-bed methane-absorption mechanism and new methods for further research of other unconventional gas reservoirs, such as the microstructural study of shale gas reservoirs.

This work was supported by the National Natural Science Foundation of China (40973051).

1 Clarkson C R, Bustin R M. The effect of pore structure and gas pressure upon the transport properties of coal: A laboratory and modeling study. 1. Isotherms and pore volume distributions. Fuel, 1999, 78: 1333-1344

2 Gilman A, Beckie R. Flow of coal-bed methane to a gallery. Transport Porous Med, 2000, 41: 1-16

3 Karacan C O, Okandan E. Adsorption and gas transport in coal microstructure: Investigation and evaluation by quantitative X-ray CT imaging. Fuel, 2001, 80: 509-520

4 Mastalerz M, Drobniak A, Strapoc D, et al. Variations in pore characteristics in high volatile bituminous coals: Implications for coalbed gas content. Int J Coal Geol, 2008, 76: 205-216

5 Radovic L R, Menon V C, Leóny León C A, et al. On the porous structure of coals: Evidence for an interconnected but constricted micropore system and implications for coalbed methane recovery. Adsorption, 1997, 3: 221-232

6 Radlinski A P, Mastalerz M, Hinde A L, et al. Application of SAXS and SANS in evaluation of porosity, pore size distribution and surface area of coal. Int J Coal Geol, 2004, 59: 245-271

7 Zhang S, Tang S, Tang D, et al. The characteristics of coal reservoir pores and coal facies in Liulin district, Hedong coal field of China. Int J Coal Geol, 2010, 81: 117-127

8 Xodot B B. Coal and Gas Outburst. Beijing: China Industry Press, 1966. 27-30

9 Gan H, Walker P L, Nandi S P. Nature of porosity in American coals. Fuel, 1972, 51: 272-277

10 Zhang $\mathrm{H}$. Genetical type of proes in coal reservoir and its research significance (in Chinese). J Coal Sci Eng, 2001, 26: 40-44

11 Veeco Instruments Inc. Nanocope Software 6.13 User Guide, 2002

12 Zhu C F, Wang C. Progress in Applications of Scanning Probe Microscopy (in Chinese). Beijing: Chemical Industry Press, 2007. 2-6

13 Benitez J J, Matas A J, Heredia A. Molecular characterization of the plant biopolyester cutin by AFM and spectroscopic techniques. J Struct Biol, 2004, 147: 179-184

14 Ganning A P, Giardin T P, Faulds C B, et al. Surfactant-mediated solubilisation of amylose and visualization by atomic force microscopy. Carbohyd Polym, 2003, 51: 177-182

15 Baker A A, Helbert W, Sugiyama J, et al. New insight into Cellulose structure by atomic force microscopy shows the $I_{\alpha}$ crystal phase at near-atomic resolution. Biophys J, 2000, 79: 1139-1145

16 Can M F, Çınar M, Benli B, et al. Determining the fiber size of nano structured sepiolite using atomic force microscopy (AFM). Appl Clay Sci, 2010, 47: 217-222

17 Wang Z, Jiao N. Tung S, et al. Research on the atomic force micros- copy-based fabrication of nanochannels on silicon oxide surfaces. Chinese Sci Bull, 2010, 55: 3466-3471

18 Yumura M, Ohshima S, Kuriki S, et al. Atomic force microscopy observations of coals. In: Proceedings of International Conference on Coal Science 1. Tsukuba: NIMC, 1993. 394-397

19 Lawrie G A, Gentle I R, Fong C, et al. Atomic force microscopy studies of Bowen basin coal macerals. Fuel, 1997, 76: 1519-1526

20 Cohen A D, Bailey A M, Myrick M L, et al. Applications of atomic force microscopy to study of artificially coalified peats. Soc Org Petrol, 1998, 15: 23-27

21 Bruening F A, Cohen A D. Measuring surface properties and oxidation of coal macerals using atomic force microscope. Int J Coal Geol, 2005, 63: 195-204

22 Golubev Y A, Kovaleva O V, Yushkin N P. Observations and morphological analysis of supermolecular structure of natural bitumens by atomic force microscopy. Fuel, 2008, 87: 32-38

23 Yang Q, Pan Z G, Tang D Z, et al. STM and AFM study of coal structure (in Chinese). Chinese Sci Bull, 1994, 39: 633-635

24 Chang Y M, Yang H G, Ma T W, et al. Study of the coal microstructure based on AFM (in Chinese). Modern Sci Ins, 2006, 6: 71-72

25 Liu J, Jiang X, Huang X, et al. Morphological characterization of super fine pulverized coal particle. Part2. AFM investigation of single coal particle. Fuel, 2010, 89: 3884-3891

26 Junno T, Deppert K, Montelius L, et al. Controlled manipulation of nanoparticles with an atomic force microscope. Appl Phys Lett, 1995, 66: 3627-3629

27 Hao Q. On morphogical character and origin of micropores in coal (in Chinese). J China Coal Soc, 1987, 4: 51-57

28 Loucks R G, Reed R M, Ruppel S C, et al. Morphology, genesis, and distribution of nanometre-scale pores in siliceous mudstones of the Mississippian Barnett Shale. J Sediment Res, 2009, 79: 848-861

29 Zhang X M, Zhang S A, Zhong L W. Coal Bed Methane in China (in Chinese). Xi' an: Shanxi Science and Technology Press, 1991. 82-84

30 Su X B, Zhang L P, Lin X Y. Influence of coal ranks on coal adsorption capacity (in Chinese). Nat Gas Ind, 2005, 25: 19-21

31 Zhao X L, Tang D Z, Xu H, et al. Effect of coal metamorphic process on pore system of coal reservoirs (in Chinese). J Chin Coal Soc, 2010, 35: 1506-1511

32 Wu J, Jin K L, Tong Y D, et al. Theory of coal pores and its application in evaluation of gas outburst proneness and gas drainage (in Chinese). J Chin Coal Soc, 1991, 16: 86-95

33 Qin Y. Micropetrology and Structural Evolution of High-rank Coal in China (in Chinese). Xuzhou: China University of Mining and Technology Press, 1995. 48-134

34 Chalmers G R L, Bustin R M. The organic matter distribution and methane capacity of the lower Cretaceous strata of northeastern British Columbia, Canada. Int J Coal Geol, 2007, 70: 223-239

35 Jarvie D M, Hill R J, Ruble T E, et al. Unconventional shale-gas systems: the Mississippian Barnett Shale of north central Texas as one model for thermogenic shale-gas assessment. AAPG Bull, 2007, 91: 475-499

36 Hover V C, Peacor D R, Walter L M. Relationship between organic matter and authigenic illite/smectite in Devonian Black Shales, Michigan and Illinois Basins, USA. In: Crossey L J, Loucks R G, Totten M W, eds. Siliciclastic Diagenesis and Fluid Flow: Concepts and Applications. Tusal: SEPM, 1996. 73-83

37 Hirono T, Lin W, Nakashima S. Pore space visualization of rocks using an atomic force microscope. Int J Rock M Sci, 2006, 43: $317-320$

38 Stoeckli F, Hugi-Cleary D, Centenob T A. The Characterization of solids by adsorption and immersion techniques and by AFM/STM. J Eur Ceram Soc, 1998, 18: 1177-1185

Open Access This article is distributed under the terms of the Creative Commons Attribution License which permits any use, distribution, and reproduction in any medium, provided the original author(s) and source are credited. 